\title{
DoIng NightLifE AND EDMC FieLdWORK
}

\author{
$\bullet$ GUeSt Editor's INTRODUCtION $\longrightarrow$ \\ LUIS-MANUEl Garcia \\ max Planck Institute for Human Development (Germany)
}

\begin{abstract}
Luis-Manuel Garcia (PhD Ethnomusicology, U Chicago, 2011) is a Postdoctoral Research Fellow at the Max Planck Institute for Human Development (Berlin, Germany), where he participates in the research group, "Felt Communities? Emotions in Musical Life in Europe". He is currently working on a book manuscript, entitled Together, Somehow: Music, Affect and Intimacy on the Dance Floor. $\mathrm{He}$ is also undertaking new fieldwork in Berlin on "techno-tourism" and expatriate life in the city's EDM scenes. He writes for Resident Advisor, Little White Earbuds and his own blog, LMGMblog:

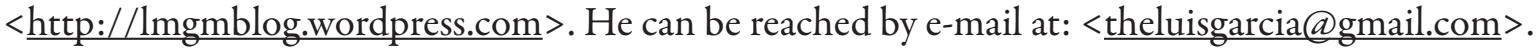

THE instructional GUide to DOING FIELDWORK in nightclubs and bars has yet to be written. But, considering the continued rise in scholarship of electronic dance music cultures (EDMC), it seems that a critical examination of its fieldwork methods is well overdue. For more than twenty years now, young scholars of EDMC have had to approach their fieldwork more or less on their own, adapting methods from their home disciplines and scavenging "tips and tricks" from those working in similar contexts. Certainly, when I began my first project studying the house and techno scenes of Paris, Chicago and Berlin, I wished that other nightlife-researchers were more open about their methods-and more generous about giving advice to new ethnographers of nocturnal scenes. But most EDMC research to date remains taciturn or vague when it comes to the concrete details of fieldwork. Admittedly, this may have something to do with the more salacious and illicit aspects of nightlife; perhaps scholars do not want to disclose what they did to get "insider" access. But perhaps they are hiding a more embarrassing secret, too: maybe they didn't know what they were doing, either.

This special issue of Dancecult sets out to redress this lack of methodological guidance and reflection. The essays collected here do not form a comprehensive guide to fieldwork in

Dancecult: Journal of Electronic Dance Music Culture 5(1): 3-17

ISSN 1947-5403 @2013 Dancecult http://dj.dancecult.net

DOI: 10.12801/1947-5403.2013.05.01.01

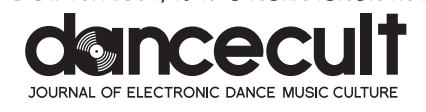


EDM scenes, but rather the beginning of a methodological discourse that will benefit both new and seasoned scholars in this field of study. The contributors to this volume recount their own fieldwork experiences, interrogate methodological conventions, highlight the particularities of nightlife fieldwork and propose new methods that are tailored to EDM contexts. In doing so, they all show a great deal of courage and candor, laying bare their own fieldwork methods and disclosing both successes and failures in order to jump-start the discussion.

In social science's most prominent ethnographic disciplines, such as anthropology, sociology and folklore studies, there already exists a robust literature on fieldwork methods, from didactic to critical to experimental. But these "top-level" disciplines span a wide range of sites, scenes and themes, so the guidance they provide can often be too general, leaving the budding EDMC researcher to adapt these models to nightlife contexts. Furthermore, these disciplines have grown out of particular places and political contexts (e.g. current and former colonies, rural Europe, indigenous communities), and thus many established methodological conventions assume field conditions that are not pertinent to EDMC studies.

One can nevertheless find valuable methodological insights in specific sub-disciplines and neighboring, thematically related fields. For example, one can find reflections on ethnographic methodology in popular music (Maxwell 2002), ethnomusicology (Barz and Cooley 1997; Myers 1992), dance studies (Buckland 1999), and theater/performance studies (Kershaw and Nicholson 2011; Smith 2009). Across several disciplines, there are also instructive and critical interventions to be found on field-notes and the writing of ethnography (Clifford and Marcus 1986; Emerson, Fretz and Shaw 2011; Marcus 2002, 2012; Markham 2005; Van Maanen 1988). Certain fields have already developed a substantial discourse on nightlife fieldwork, such as youth studies (Blackman 2007; Hodkinson 2005; Hunt, Moloney and Evans 2010; Le Breton 2004; Lyng 2005) and public health / epidemiology / drug use studies (Adler 1990; Demant, Ravn, and Thorsen 2010; Hunt, Moloney and Evans 2009; Measham and Moore 2006; Moore 2002). The reflexive turn in the social sciences also produced important accounts of the impact of gender and sexuality on fieldwork methods (Allison 1994; Gurney 1985; Perrone 2010; Rambo Ronai 1992; Sanders 2006), although much more remains to be done on this topic as well as on race, class, ethnicity, ability and other identity-categories. Finally, research on mobility and translocal networks has been producing a range of "mobile methods" that can prove useful for scholars of EDM's increasingly mobile scenes (Büscher, Urry and Witchger 2011; Marcus 1995, 1999).

Of course, researchers can always find guidance by following the example of alreadypublished EDMC research. If present at all, however, descriptions of ethnographic methods in these publications are usually tucked away discreetly in an appendix or a section of the introductory chapter. For example, only a few EDM-related monographs deal with fieldwork methods in substantial detail (Anderson 2009; Buckland 2002; Malbon 1999), while another handful address it in an indirect or glancing way (Amico 2006; Butler 2006; 
D’Andrea 2007; Fikentscher 2000; St John 2010; Thornton 1996). As is all too often the case with ethnography, these "methods" sections seem to be reluctantly written, reduced to terse and sometimes defensive prose. At any rate, these brief methodological reflections too often lack detail, do not interrogate their own methods critically and/or fail to engage critically with other EDMC ethnographers.

At present, there is a near-total lack of explicitly pedagogical materials on EDMCspecific fieldwork, and even the descriptive or critical writing that takes such fieldwork as a central theme is scant and fragmented. As this field of study grows and matures, it is becoming increasingly problematic that we have not yet developed a collective notion of what "best practices" in EDMC fieldwork would look like. This is an important ethical and disciplinary issue that we can hardly afford to ignore. One may rightly ask whether a unified pedagogy of fieldwork methods is desirable in such a diverse field, but there are nonetheless several practical, ethical and legal considerations particular to EDMC fieldwork that both new and old ethnographers should not have to face alone.

\section{The Challenges of Nightlife Fieldwork}

FIELDWORK IN EDM SCENES requires new and adapted methods because nightlife contexts themselves pose challenges that conventional ethnographic methods are ill equipped to address. Just a few of these are:

Respecting nightlives: One of the characteristic aspects of nightlife is that it provides a realm of activity that is at a remove from everyday, public, ordinary, "official" life. Many participants in nightlife scenes take advantage of this social, physical and chronological distancing to develop a "nocturnal persona" (Grazian 2005, 2008)—or, indeed, multiple personae-which can diverge sharply from one's daytime identity. For some, the stakes of violating the boundaries between daylife and nightlife can be very high; and, with the continuing proliferation of hand-held technologies and wireless communications, these boundaries are becoming easier and easier to breach. People often allow themselves to do things at night (in clubs, bars, bathhouses, parks, etc.) that they would not or could not during the daytime. On the one hand, some of these revelers may care little if their employer, family, or friends knew that they dance, drink, use drugs, enjoy fetish play, engage in transgressive gender performances, and so on. On the other hand, others would be mortified. And this can go well beyond embarrassment: a breach of confidentiality has the potential to precipitate a loss of employment, social estrangement and even physical harm. So, how should the researcher respect the boundaries between participants' various life-worlds? One of the primary challenges of nightlife fieldwork is thus to gain access, collect data, store sensitive information, and finally publish — to make public - information on a social world that relies on the avoidance of public scrutiny to sustain its experiments in living differently.

Establishing trust in "underground" scenes: If you are doing fieldwork, you need accessto people, to spaces, to information, to events, to personal archives-and access only comes 
with trust. You need to know what is going on in the scene, you need people to open up to you and tell you their stories, you need to hear about and attend the events that make the scene what it is. And yet, participants in "underground" scenes have very good reasons to be wary of inquisitive scholars and journalists: part of underground scenes' self-ascribed subcultural value is their low visibility, while increased visibility has historically been associated with some form of harm to the scene. What little information about underground scenes that does reach the general public — often through journalists and ethnographers-has a history of being distorted and damaging. For example, most rave scenes were hit with a "moral panic" (Hier 2002; Thornton 1996) at some point during the 1990s, much of which was facilitated by outsiders gaining access to the rave scene and then publishing reports that portrayed raves as teenaged drug-and-sex orgies. This had a very real and lasting impact on the rave scenes of the 90s, leading to police crackdowns, legislative bans, and the criminalization of rave promoters. Along with journalists and social scientists in criminology, epidemiology and drug-use studies, ethnographers have played a significant role in producing the kind of institutionally backed knowledge that provided political fodder for anti-rave measures. How will partygoers know that you'll be any different?

No photos, please: During my training as an ethnomusicologist, one of the few explicit methodological directives I received was that ethnomusicologists should be creating their own research archive by recording as much as possible (e.g. Myers 1992). Photos, audio recordings and videos all have important talismanic value to the discipline as proof that what we are doing is "serious" and "scientific" fieldwork. Moreover, recording would provide us with objects to analyze, while also providing "objective" evidence to support our own phenomenological descriptions of musical culture. This pressure to document is also present in most social sciences, and so it permeates the practice of fieldwork as well. But how do you get consent from a crowd of partygoers who may not want their drunk, high, and/or sweaty faces popping up in your next blog post, journal article, or conference presentation? How do you know that the DJ/band/artists do not mind that you are recording their performance? Some EDM events are already saturated with camera-phones and other recording devices, while others enforce strict camera bans-both for reasons of privacy and intellectual property. And even when there is no explicit ban on recording, how socially acceptable will it be for you to whip out a camcorder at the next event? Conversely, when is it more important to do something socially inappropriate in the name of "good data?" Of what analytic and representative value will this data be if its collection is socially disruptive? Some EDM scenes are admittedly eager to document themselves, thus generating an ersatz archive of promotional videos, "user content" on social media, online event reviews, magazine photographs and even self-made documentaries. When available, these resources are indeed valuable-albeit often biased as self-promotional. But regardless of the local norms around recording media, the question remains: How do you collect "data" without alienating the people around you?

Respecting fun: Interrupting fun is a genuine ethical problem when the fieldwork site is also a site of leisure for its participants. Most EDM-event participants go out to have fun, 
dance, enjoy music, drink, get high, get off, feel good, be spontaneous, be risky, cut loose, feel special, be weird, etc. One can assume that they do not go out to an EDM event to complete a survey or engage in a probing interview. In a way, participants are busy having fun; how do you avoid interrupting that while you do your fieldwork? Ethically, this is more important than the word "fun" may imply: partygoers invest time, effort, and resources into seeking out experiences that provide them with consolation, empowerment, validation, distraction, relief, ecstasy, or simply an escape from the difficulties of everyday life. Is it right to interrupt their fun for our own curiosity (and professional career interests)? It would be undoubtedly problematic to interrupt participants in a religious ritual, a romantic encounter or an intimate conversation-regardless of how fun they may be-so why should we not show the same respect for participants' immersion in EDM events?

Working in noisy/chaotic environments: To put it lightly, most nightlife events entail less than optimal conditions for conducting and recording interviews, taking pictures, video and so on. But music events are the heart of most dance music scenes, bringing together performing, listening, dancing, curatorship/connoisseurship, face-to-face interactions and economic exchanges. If such events cannot be missed, which research methods can be conducted in a loud, dark, smoky place that is erratically lit by flashing lights?

What do you have to offer? Due to anthropology's origins in colonialism (and sociology's early involvement in the "management" of the lower classes), ethnographers have been able to take advantage of their relative wealth, intellectual prestige, institutional support and perceived connections to Western modernity to attract interlocutors. For those working with underprivileged, poor and/or low-status groups, such asymmetries can work to their advantage-especially if group members also see an advantage in having their cultural practices studied as "culture" and "tradition". But for ethnographers of EDMCsparticularly young ethnographers who are still living on graduate/post-graduate income-it is often the case that their potential fieldwork consultants earn more money than they do, enjoy more social privileges, and have little concern for the academic validation of their nocturnal pursuits. As ethnographers, we take their time, their words and their experiences, and we make a (hopefully lucrative) career out of it; what can we offer our interlocutors in exchange?

The costs of nightlife: Most nighttime events (especially in urban centers) take place in bars, clubs, lounges, bathhouses, cafés, etc. These are all venues that make their profits by charging very high prices for beverages and usually charging a fee for entry. Also, both making and maintaining fieldwork contacts often entails the ritualized gift-exchange of paying for drinks or other consumables. All of these expenses add up to a bill that may make fieldwork too costly to undertake with any intensity; this issue is particularly pressing for young EDMC ethnographers, who most urgently need to establish their contact-networks through face-to-face socializing but also must subsist on graduate-student funding. Sure, these costs may go down slightly as one establishes connections with event-organizers and receives the occasional guest-list spot, but sustained fieldwork in nightlife scenes will always be expensive. After all, nightlife is also an industry-one that is cost-intensive but 
also potentially profitable.

Exhaustion: EDM events are almost always very athletic events that take place at very odd hours. Depending on the particularities of the local scene (available venues, liquor licenses, noise ordinances, closing times), an event may range from a 4-hour blast of focused dancing and rapid intoxication to a multi-day marathon with sporadic breaks for food and sleep. In almost every case, sleep patterns are disturbed and the body's limits of endurance are pushed. The physical and mental cost of participant-observation thus takes its toll, and these exertions unavoidably impact one's everyday, "normal" activities. This makes intensive fieldwork especially difficult to maintain when one also has responsibilities as an educator and/or scholar. How do you strike a balance? Furthermore, our resilience to disturbed sleep patterns declines with age. How long until you are "too old for this?" What can we learn about EDM cultures through our body's efforts to keep up?

Unsurprisingly, most of the challenges listed above have to do with the circumstances of EDM events themselves, which place particular demands on participation and limit certain activities. This leaves the EDMC researcher with two options: conduct fieldwork away from music events or develop adapted, limited and/or innovative methods to gather data within the limits of these events. The contributors to this special issue reflect a broader pattern among EDM scholars, who tend to combine both of these strategies in some way, conducting fieldwork both on and off the dance floor-albeit with very different procedures for each context. And this methodological bifurcation often follows the divide between the two pillars of conventional ethnographic fieldwork: participant-observation and focused interviews.

\section{DOING NightLIFE FiELDWORK}

\section{PARTICIPANT-ObSERVATION at EDM EVENTS}

PARTICIPANT-OBSERVATION IS ALREADY long established in the methodological repertoire of anthropology and sociology, and it has been increasingly adopted across a wide range of disciplines such as history, performance studies, epidemiology and music studies. Participant-observation has come to be preferred over purely non-participant observation as a means of studying living musical traditions, particularly in the fields of anthropology and ethnomusicology, as well as in certain strands of sociology that emphasize ethnographic methods, such as the Chicago School of Sociology (Bulmer 1984; Deegan 2001). At its core, the concept is very simple: take part in a cultural activity, and-over time-learn things about that activity that one would not have discovered just by watching from a distance. There is a great deal more to it, of course: the participant-observer also builds social connections into the community, prompts pedagogical interactions where experts explain the group's "unwritten rules", and develops an expertise in that activity-all of which lends credibility to the ethnographer when presenting her work to other scholars. But ongoing participant-observation also creates a sort of "archive of experience", from 
which one can draw in order to gain a more intuitive understanding of how things work, what is appropriate, what things mean, and so on.

When I have conducted participant-observation in the field, my methodological decisions have been shaped by the axiom: "Don't mess with the vibe". Using an emic term such as "vibe" as guidance may be woefully vague, but this affective dimension is as essential to music events as it is difficult to describe. A great deal of the social interactions, gestures and performances in nightlife scenes are actually rather fragile, depending on the mood and atmosphere to be right in order to find expression. I became especially sensitive to this when I was conducting fieldwork for my first ethnographic project, which focused on strangerintimacy. Many factors needed to be in just the right place in order for someone to reach out and open up to a stranger-and me pulling out a notepad or video camera certainly did not help. If event participants do not feel comfortable, they will not act as they usually do; and if one is violating norms of etiquette, privacy and/or personal space, these participants will not feel comfortable. There is a flow to every social gathering-with music playing an important role in how it flows - and a music ethnographer should know how to follow that flow without interrupting it. Mostly, this involves learning what is socially appropriate in a particular community and respecting these norms and habits. In some scenes, this might mean being talkative, tactile and physically expressive in your dancing; in other scenes, this might mean being reserved, avoiding physical contact and showing quiet respect for the performer. One of the first tasks during the researcher's early fieldwork phase is to figure out what works in these contexts.

In response to these concerns, the principal fieldwork technique that I have developed for participant-observation at EDM events could be described as "memory work". During my time at an EDM event, I focus on "being there": taking note of and interacting with the music, the people and the environment. Then, when I return home (or immediately after I wake up the next morning), I write down as much as I can recall from the event-including any details that I have retained, such as verbatim quotations, particular music tracks played, clothing, décor and so on. In the days following the event, I will return to these point-form notes and revise them into a smoother narrative. Then, when I am in a writing phase, I can return to these notes and have a detailed archive of ethnographic data at my disposal. This sort of memory work was difficult at first, but I found that the depth and precision of my memory increased with practice: after my first three months of intensive fieldwork, I had developed the capacity to recall entire conversations. However, the chief disadvantage of this approach is that such detailed memory is rather volatile; if I did not write my notes within two or three days of the event, I found that I could not recall the small gestures, facial expressions, overheard comments, recognized tracks and other details that make ethnography come alive.

This does not mean that I have completely avoided any form of note-taking, but I have strived to keep such activity as discreet and as brief as possible. After all, a musical event is something that happens in real time, and any time spent scribbling or recording is time lost from noticing what is happening around you. So-called "smart phones" (i.e., internet-enabled 
phones that can run applications) have been particularly helpful in facilitating quick and discreet note-taking. Most models have some sort of "notepad" function or program, and typing notes into such an application on one's phone usually looks very similar to sending an SMS message or checking one's e-mail. Smart phones and point-and-shoot cameras also provide a convenient means of taking photographs and recording short video clips, although I usually wait to see if other participants are taking pictures before bringing out my own camera. When I do take photos or video, I make sure to avoid framing anybody's face in the image; instead, I usually try to get a "wide" shot of the whole crowd or the venue. As mentioned earlier, event-participants themselves will sometimes record and upload media from the event to social networking sites such as YouTube, Facebook, Flickr, Vimeo, Twitter or Instagram (to name a few). These can provide useful resources for research, although one should always consider whether the original footage/images were taken ethically and should ask for permission before reproducing them in one's own published work.

In summary, most of my methodology for "going out" as an ethnographer is based on a concern for not letting the observation of the event get in the way of the event itself. Based on conversations with other EDM researches, I do not seem to be alone in using this approach, but there also exist substantially different approaches that prioritize different issues and thus produce different kinds of knowledge. For example, I avoid formalized interviews at events, instead remaining open to more spontaneous discussions, relying on my memory to retain the gist of casual conversations, and conducting formal interviews off-site. But other researchers have strived to find ways to conduct more structured interviews on-site, often at the spatial (and sonic) margins of these events. These raise issues around consent, recording and conspicuousness that I did not have to deal with. Such diversity in methodology is valuable and contributes to the robustness of this field of research, and so it is all the more crucial that we discuss and exchange ideas about how we work in these environments.

\section{INTERVIEWING PARTY PEOPLE}

IN MANY WAYS, AN off-site interview with an EDM participant sufficiently resembles the conditions of conventional ethnographic fieldwork for "mainstream" guidebooks on interviewing to be immensely helpful. However, while ethnographic interviews may seem straightforward, interviewing within EDM scenes also poses some particular challenges. These challenges become clearer when one considers some of the basic questions of preinterview preparation. Considering that the interviewee's time is limited, how many questions will you ask and which will take priority? How do you get interviewees in the first place? How will you protect the interviewee's identity? Will you record the interview, take handwritten notes, or both? Where will you conduct the interview? Will you ask uncomfortable questions? How will you analyze the interview afterwards?

Making connections and securing interviews-"recruiting", as it is often termed in methodological discourse-can be especially challenging in EDM scenes. Due to most scenes' self-image as an "underground" community and its frequent association with notentirely-legal activities, the ethnographer must contend with heightened concerns about 
confidentiality as well as doubts about the interviewer's intentions. Activities at nightlife events can be transgressive, scandalous, embarrassing, compromising and sometimes clearly illegal; the stakes of privacy and discretion are thus much higher than in everyday settings, and scene participants are justifiably concerned about what you are going to do with their information and how you will protect it. As a result, the researcher must find ways to address these concerns and overcome these barriers.

In my own fieldwork, I have come rely on what I call a "trust network" to support my requests for interviews. This means making social connections first-often through the introduction of a mutual contact, but sometimes directly-and taking time to develop that connection into a relationship of trust. Essentially, this is a form of Kontaktpflege (German: cultivation of contacts), which allows the contact-person to become more familiar with me and to develop a sense that I am not likely to harm them in some way. This can take weeks and months, and often involves repeatedly meeting for coffee/drinks, attending music events together, attending her/his events if $s /$ he is a performer or promoter, exchanging e-mails, maintaining contact through social networking sites, and revealing more about myself and my own relationship to the local music scene. This method of recruiting is obviously best suited to long research phases, as it may take months to establish a sufficient rapport to be certain for an interview. The advantage, however, is that one can often secure interviews with scene-actors who would otherwise be very reluctant to speak with a researcher.

One of the other advantages to developing a trust network is that existing contacts in this network can assist me in making new fieldwork contacts by providing contact information, making introductions and vouching for my bona fides as a trustworthy person. In this sense, what I describe here is similar to the well-known recruiting method often called "snowball sampling", wherein the researcher asks each interviewee to recommend other potential interviewees for the project. This method has been especially valuable in research that focuses on "hidden" and "hard to reach" populations, such as youth subcultures, drug users, sexual minorities and sex workers (Adler 1990; Biernacki and Waldorf 1981; Demant, Ravn and Thorsen 2010). And so, to the extent that a given EDM scene avoids visibility and includes illicit activities and/or stigmatized identities, snowball sampling can be a powerful recruiting tool.

This method also has its drawbacks, however, most of which have to do with the risk of skewed results. Essentially, developing one's pool of contacts through snowball sampling risks producing an ethnography of a particular social network, rather than of an entire community or scene; that is, one risks mistaking the quirks of a single, interconnected social group for the characteristic traits of an entire population. On the one hand, there is nothing inherently wrong with developing a richly-detailed account of an interrelated group of people; on the other hand, it limits the truth-claims that one can make about the larger world of nightlife. There is no simple solution to this issue. In my own work, I strive to mitigate this methodological weakness by working hard to develop contacts beyond the extended networks of those people I already know. This entails going out and meeting strangers, being outgoing, engaging in small talk, and becoming a "familiar face" at important venues and events - all of which require substantial time and effort. 
Finally, confidentiality is an especially important consideration for EDM fieldwork, although these concerns do not differ greatly in their nature from those found in the ethnography of "hidden" populations, and so one can find a great deal of guidance in already-established practices. These include such practices as the preparation of an informed consent "script" (whether verbal or written), the use of pseudonyms, the storage of research files and interview recordings in locked cabinets and/or on encrypted digital media, and the consultation with interviewees during the writing process to ensure that quotations do not expose their identities or misrepresent them. Nonetheless, one issue that may arise in EDM fieldwork concerns scene-actors who are also publicly-known performers and/or promoters: on the one hand, it may become difficult to conceal their identities as they disclose details about their biography and musical practices; on the other hand, they may explicitly request that their real name or artist's moniker be used in order to raise their own public profile. There are no simple solutions or guidelines for dealing with these issues; such blurring of the boundaries between public and private identities requires vigilance, diligence and deft writing.

\section{Other Modes of Nightlife FieldWork}

CERTAinly, ATTENDING EDM EVENTS and conducting one-on-one interviews are not the only possible modes of doing fieldwork. Scholars in the social sciences continue to develop new and experimental fieldwork methods, and this is also the case in this special issue. The contributions to this volume push fieldwork in new directions, such as in Alice O'Grady's use of theatrical performances at EDM events as a means to engage other partygoers through a mode of activity that is already indigenous to the scene, i.e., play. Similarly, madison moore explores how organizing an event can also be a mode of ethnographic research, forcing the researcher to take a more holistic view of the dance event and to give more attention to its practical, organizational, promotional and "backstage" aspects. Some contributors also adapt existing methods to nightlife contexts, such as Bina Bhardwa's "shadowing" of fieldwork contacts during an EDM event, which helps her process her own experiences as a female, South Asian researcher in a male-dominated and heteronormative environment. Sheena Hyndman finds herself adapting her methods to sharply contrasting environments, as she moves the focus of her research away from the dance floor and out to gyms, schoolrooms and cafés. And, as nearly every essay in this volume shows, participantobservation can go well beyond the boundaries of the EDM event: much can be learned about these music scenes through a sort of "deep hanging out" (Geertz 2000) that can also take place during the more mundane hours of the week. ${ }^{1}$

\section{IN THIS ISSUE}

THE ESSAYS IN THIS special issue of Dancecult explore and address many of the concerns raised in this introduction. Todd Rosendahl, for example, contends with queer partygoers' concerns about confidentiality and the boundaries between context-specific identities, reflecting on how his own sexuality may affect how he establishes trust with his interlocutors. 
Similarly, Bina Bhardwa recounts how her multiple identities as young, female and South Asian pose challenges to her ability to be taken seriously as a knowledgeable researcherand yet these same identifications sometimes permit her moments of candid insight and solidarity with other minoritized partygoers. Caitlin Robinson, in her insightful analysis of local celebrity and wasta [social connectedness/influence] in Beirut's club scene, considers how her gender, body shape, skin tone, language skills, nationality, perceived ethnicity, dress and level of education all impact her fieldwork experience as well as the wasta of the local celebrity DJ that she frequently accompanies on nights out. Additionally, Bhardwa and Robinson both consider the question of reciprocity between ethnographers and their fieldwork consultants: what can they offer in exchange for information? What do their interlocutors think they are offering?

Many authors focus on developing new and adapted fieldwork methodologies better suited to EDM settings. Both O'Grady and moore bring performance studies to bear on EDM fieldwork, albeit with very different results. O'Grady replaces static observation with dynamic play, preserving the "flow" of the EDM festivals she studies by staging interactive performances with a team of co-researchers/co-performers. For moore, throwing a party is fieldwork method itself: he argues that the organization of EDM events offers the researcher crucial and unique insights into how EDM scenes work. Looking back to the example of New York's most famous disco-era club, Studio 54, he shows how a theatrical lens can reveal the extent to which nightlife is staged and curated by subcultural impresarios. Sheena Hyndman explores EDM fieldwork away from the dance floor and outside of "nightlife" proper, adapting conventional ethnographic methods to listening practices that are rarely given attention in EDM studies. Finally, in the first installment of the new translation series, "Transcriptions", Jan-Michael Kühn adapts Hubert Knoblauch's method of "focused ethnography" to the study of EDM producers in their home-recording studios, presenting an approach that is suitable for short, intense periods of fieldwork in narrowly-focused fields-which is of particular interest to those scholars who cannot engage in long-term, sustained fieldwork (e.g. junior faculty, adjunct lecturers, graduate students, independent scholars).

A final cluster of contributions to this issue focuses on the problem of documenting and representing the fieldwork experience. This is an issue for any kind of ethnography, but it is especially pressing for the intense, multisensory and socially-dense experiences within EDMCs. Tami Gadir's response to this problem is to combine spoken word, a mixed DJ set, and field recordings to create a sound-collage that reflects on the nature of EDM fieldwork while also powerfully evoking its sonic environments. Graham St John's essay on "Writing the Vibe" argues for a "radical empiricism of the vibe" in ethnographic writing, calling for a more creative, experimental and "sampladelic" approach that interweaves fragmentary representations ("nanomediations") of various aspects of EDMC experience. Finally, Lars Nørr Mikkelsen offers us a typology and genre-study of ethnographic field-notes, drawing from a pool of documents from a study of Danish nightlife venues to show how researchers produce field-notes that follow certain narrative and stylistic conventions. 
This special issue of Dancecult is not intended to be an early draft of a handbook, guidebook or textbook. The goal here is not to be definitive, comprehensive or prescriptive. Instead, it is the beginning of a conversation that we must sustain if EDMC studies are to grow into the robust field of scholarship that these music scenes deserve. As scholars of various styles of electronic dance music, we have all experienced the frustration of finding our home discipline's fieldwork methods impractical and sometimes impracticable for our ethnographic sites. Individually and through informal conversations, EDM scholars have been developing their own solutions to this gap in methodology; but there is no reason for us to continue struggling alone. It is long past time that we present our own methods, critically interrogate them, propose new ones and build something better together.

\section{ACKNOWLEDGEMENTS}

I would like to thank the editorship of the IASPM-US Blog (International Association for the Study of Popular Music, US Chapter) for publishing my three-part essay series, "Doing Nightlife Fieldwork" (Garcia 2012). The response to that series provided the first impetus for this special issue of Dancecult. This introductory essay is partially based on text from this earlier series. I would also like to thank the "Berlin Program for Advanced German Studies" at the Free University of Berlin-with special thanks to its coordinator, Karin Goihl-for their support during the preparation of this special issue. I am also grateful to the Max Planck Institute for Human Development as well as the Max-Planck-Gesellschaft for providing support during the final phase of this publication. Many thanks go out to the scholars published in this issue for their valued contributions as well as their efforts during the editing process. And, of course, my heartfelt thanks to the Dancecult editorial team for their tireless efforts in bringing this issue to publication. I am especially grateful to Executive Editor Graham St John for taking a chance on this special issue.

\section{NOTES}

1 However, one of the disadvantages of having a "fun" field of research is that it is often difficult to have such hanging out recognized as "serious" research by our colleagues (and grant-giving bodies).

\section{REFERENCES}

Adler, Patricia. 1990. "Ethnographic Research on Hidden Populations: Penetrating the Drug World". In The Collection and Interpretation of Data from Hidden Populations, ed. Elizabeth Y. Lambert, 96-112. Rockville, MD: National Institute on Drug Abuse.

Allison, Anne. 1994. Nightwork: Sexuality, Pleasure, and Corporate Masculinity in a Tokyo Hostess Club. Chicago: University of Chicago Press.

Amico, Stephen. 2006. "Su Casa Es Mi Casa: Latin House, Sexuality, Place”. In Queering the Popular 
Pitch, ed. Sheila Whiteley and Jennifer Rycenga, 131-51. New York: Routledge.

Anderson, Tammy L. 2009. Rave Culture: The Alteration and Decline of a Philadelphia Music Scene. Philadelphia: Temple University Press.

Barz, Gregory F. and Timothy J. Cooley. 1997. Shadows in the Field: New Perspectives for Fieldwork in Ethnomusicology. New York: Oxford University Press.

Biernacki, Patrick and Dan Waldorf. 1981. "Snowball Sampling: Problems and Techniques of Chain Referral Sampling”. Sociological Methods \& Research 10(2): 141-63.

Blackman, Shane J. 2007. “'Hidden Ethnography”: Crossing Emotional Borders in Qualitative Accounts of Young People's Lives”. Sociology 41(4): 699-716.

Buckland, Fiona. 2002. Impossible Dance: Club Culture and Queer World-Making. Middletown, CT: Wesleyan University Press.

Buckland, Theresa. 1999. Dance in the Field: Theory, Methods, and Issues in Dance Ethnography. Basingstoke: Macmillan.

Bulmer, Martin. 1984. The Chicago School of Sociology: Institutionalization, Diversity, and the Rise of Sociological Research. Chicago: University of Chicago.

Büscher, Monika, John Urry and Katian Witchger. 2011. Mobile Methods. Abingdon, Oxon: Routledge.

Butler, Mark J. 2006. Unlocking the Groove: Rhythm, Meter, and Musical Design in Electronic Dance Music. Bloomington, IN: Indiana University Press.

Clifford, James, and George E. Marcus. 1986. Writing Culture: The Poetics and Politics of Ethnography. Berkeley: University of California Press.

D’Andrea, Anthony. 2007. Global Nomads: Techno and New Age as Transnational Countercultures in Ibiza and Goa. London: Routledge.

Deegan, Mary Jo. 2001. "The Chicago School of Ethnography”. In Handbook of Ethnography, eds. Paul Atkinson, Sara Delamont, Amanda Coffey, John Lofland and Lyn Lofland, 11-25. London: Sage.

Demant, Jakob, Signe Ravn and Sidsel Kirstine Thorsen. 2010. "Club Studies: Methodological Perspectives for Researching Drug Use in a Central Youth Social Space”. Leisure Studies 29(3): $241-52$.

Emerson, Robert M., Rachel I. Fretz and Linda L. Shaw. 2011. Writing Ethnographic Fieldnotes. 2nd ed. Chicago: University of Chicago Press.

Fikentscher, Kai. 2000. "You Better Work!": Underground Dance Music in New York City. Hanover, $\mathrm{NH}$ : Wesleyan University Press.

Garcia, Luis-Manuel. 2012. "Doing Nightlife Research”. IASPM-US Blog (International Association for the Study of Popular Music, US Chapter) (3 parts), <http://iaspm-us.net/?p=1476>.

Geertz, Clifford. 2000. Available Light: Anthropological Reflections on Philosophical Topics. Princeton, NJ: Princeton University Press.

Grazian, David. 2005. Blue Chicago: The Search for Authenticity in Urban Blues Clubs. Chicago: University of Chicago Press.

- - . 2008. On the Make: The Hustle of Urban Nightlife. Chicago: University of Chicago Press.

Gurney, Joan Neff. 1985. "Not One of the Guys: The Female Researcher in a Male-Dominated Setting". Qualitative Sociology 8(1): 42-62. 
Hier, Sean. 2002. "Raves, Risks and the Ecstasy Panic: A Case Study in the Subversive Nature of Moral Regulation”. Canadian Journal of Sociology 27(1): 89-105.

Hodkinson, Paul. 2005. “Insider Research' in the Study of Youth Cultures”. Journal of Youth Studies 8(2): 131-49.

Hunt, Geoffrey, Molly Moloney and Kristin Evans. 2009. "Epidemiology Meets Cultural Studies: Studying and Understanding Youth Cultures, Clubs and Drugs". Addiction Research \& Theory 17(6): 601-21.

- - 2010. Youth, Drugs, and Night Life. New York, NY: Routledge.

Kershaw, Baz and Helen Nicholson. 2011. Research Methods in Theatre and Performance. Edinburgh: Edinburgh University Press.

Le Breton, David. 2004. “The Anthropology of Adolescent Risk-Taking Behaviours”. Body \& Society 10(1): 1-15.

Lyng, Stephen. 2005. "Edgework and the Risk-Taking Experience". In Edgework: The Sociology of Risk-Taking, ed. Stephen Lyng, 3-16. New York: Routledge.

Malbon, Ben. 1999. Clubbing: Dancing, Ecstasy and Vitality. New York: Routledge.

Marcus, George E. 1995. "Ethnography in/of the World System: The Emergence of Multi-Sited Ethnography”. Annual Review of Anthropology 24: 95-117.

- - 1999. "What is at Stake—and is not—in the Idea and Practice of Multi-Sited Ethnography". Canberra Anthropology 22(2): 6-14.

- _ - 2002. "Beyond Malinowski and after Writing Culture: On the Future of Cultural Anthropology and the Predicament of Ethnography”. The Australian Journal of Anthropology 13(2): 191-99.

- - - 2012. "The Legacies of Writing Culture and the Near Future of the Ethnographic Form: A Sketch". Cultural Anthropology 27(3): 427-45.

Markham, Annette N. 2005. “'Go Ugly Early': Fragmented Narrative and Bricolage as Interpretive Method". Qualitative Inquiry 11(6): 813-39.

Maxwell, Ian. 2002. “The Curse of Fandom: Insiders, Outsiders and Ethnography”. In Popular Music Studies, ed. David Hesmondhalgh and Keith Negus, 103-16. London: Arnold.

Measham, Fiona and Karenza Moore. 2006. "Reluctant Reflexivity, Implicit Insider Knowledge and the Development of Club Studies". In Drugs, Clubs and Young People: Sociological and Public Health Perspectives, ed. Bill Sanders, 13-25. Aldershot: Ashgate.

Moore, David. 2002. "Ethnography and the Australian Drug Field: Emaciation, Appropriation and Multidisciplinary Myopia”. International Journal on Drug Policy 13(4): 271-84.

Myers, Helen. 1992. Ethnomusicology: An Introduction. 1st ed. New York: W.W. Nortion.

Perrone, Dina. 2010. "Gender and Sexuality in the Field: A Female Ethnographer's Experience Researching Drug Use in Dance Clubs”. Substance Use \& Misuse 45(5): 717-35.

Rambo Ronai, Carol. 1992. "The Reflexive Self Through Narrative: A Night in the Life of an Erotic Dancer". In Investigating Subjectivity: Research on Lived Experience, ed. Carolyn Ellis and Michael C. Flaherty, 102-24. Newbury Park, CA: Sage.

Sanders, Teela. 2006. "Sexing Up the Subject: Methodological Nuances in Researching the Female Sex Industry”. Sexualities 9(4): 449-68.

Smith, Hazel. 2009. Practice-led Research, Research-led Practice in the Creative Arts, Research 
Methods for the Arts and Humanities. Edinburgh: Edinburgh University Press.

St John, Graham. 2010. The Local Scenes and Global Culture of Psytrance. New York: Routledge. Thornton, Sarah. 1996. Club Cultures: Music, Media and Subcultural Capital. Hanover, NH: Wesleyan University Press.

Van Maanen, John. 1988. Tales of the Field: On Writing Ethnography. Chicago: University of Chicago Press. 